\title{
COMPORTAMENTO DOS PRECCOS DOS PRODUTOS DERIVADOS DA OVINOCULTURA NO RIO GRANDE DO SUL NO PERÍODO DE 1973 A 2005
}

\author{
Price tendency of sheep products in the state of Rio Grande do Sul from 1973 to 2005
}

\author{
João Garibaldi Almeida Viana', Renato Santos de Souza²
}

\begin{abstract}
RESUMO
O conjunto de mudanças estruturais e conjunturais por que passou a atividade ovina nas últimas décadas refletiu-se nos preços pagos pelos seus produtos, seja na fase de declínio como de recuperação recente. Assim, com este trabalho, procura-se identificar o comportamento dos preços pagos ao produtor no Rio Grande do Sul pelos principais produtos da ovinocultura, carne de ovelha, carne de cordeiro e lã, no período de 1973 a 2005, enfatizando as características de tendência, sazonalidade e ciclos de preços. Com base em dados primários de preços coletados pela EMATER-RS, observou-se que os preços reais apresentaram tendência de queda no período de 1973 a 1994. Entretanto, a estabilização econômica do Plano Real e suas conseqüências no mercado interno fizeram com que a carne ovina se tornasse o produto principal da ovinocultura, apresentando considerável elevação de preços no período de 1995 a 2005. Observou-se também que o período pós 1995 é marcado por redução na intensidade das variações interanuais e sazonais de preços. Pode-se dizer, então, que após 1995 a ovinocultura passa por uma recuperação de preços em termos reais e por uma estabilização nos mercado, o que aumenta a rentabilidade e reduz os riscos da atividade.
\end{abstract}

Termos para indexação: Ovinocultura, preços pagos ao produtor, séries temporais.

\begin{abstract}
The structural changes through which sheep production sector has been through in the last decades has had a direct effect in the prices of its the products. There was periods of decline and recent period of recovering. In this study we analyse the tendency of prices paid to the farmer in the state of Rio Grande do Sul for the main sheep products: sheep meat, lamb meat and wool, from 1973 to 2005, with emphasis on tendency, seasonal and price cycle characteristics. Based on primary data collected by EMATER-RS, it could be perceived that adjusted prices presented a tendency to decline between 1973 and 1994. However, the economic stabilization brought by the "Plano Real" and its consequences on the internal market made meat become the main sheep product, presenting considerable price increase from 1995 to 2005. It was also observed that this last period is characterised by a reduction in the intensity of inter annual and seasonal price variation. Thus, it can be said that after 1995 sheep production underwent adjusted price recovering and market stabilisation, which increases profitability and reduces the risks of carrying out this activity.
\end{abstract}

Index terms: Sheep production, farming prices, time series.

(Recebido para publicação em 6 de junho de 2006 e aprovado em 20 de setembro de 2006)

\section{INTRODUÇÃO}

A ovinocultura no Rio Grande do Sul teve papel fundamental no progresso da pecuária gaúcha. Durante o século XX a atividade evoluiu promovendo desenvolvimento econômico e social e posicionando o estado como um dos maiores produtores do País.

A ascensão da ovinocultura teve começo nas primeiras décadas do século XX, que segundo Nocchi (2001), resultou da valorização da lã decorrente da primeira guerra mundial, que causou elevação no preço do produto e despertou o interesse dos produtores pela atividade.

A produção ovina atravessou períodos de crises e progressos. Bofill (1996) relata que a década de 40 foi extremamente rica, marcada pelo surgimento de grandes organizações que deram respaldo ao crescimento do setor.
Durante as décadas de 50 e 60 a atividade se consolidou como a maior riqueza existente nos campos gaúchos, com o produto lã sustentando todas as necessidades das estâncias. A década de 70, porém, foi caracterizada pelo apoio à agricultura e pelo começo do avanço da lavoura sobre as áreas de pecuária. A mudança de orientação do crédito rural, a queda do preço da lã no mercado internacional e a falta de subsídios para as cooperativas configuraram um contexto de dificuldades para a ovinocultura durante a década de 80.

No decorrer da década de 90 os problemas aumentaram, os preços da lã continuaram a cair devido aos altos estoques australianos e à entrada de tecidos sintéticos no mercado. Nocchi (2001) ressalta que outros fatores durante a década de 90 também influenciaram na

'Zootecnista, Mestrando em Extensão Rural - Núcleo de Estudos e Pesquisas em Economia Agroindustrial/NEPEA - Universidade Federal de Santa Maria/UFSM - Rua Pinheiro Machado 2694, apto 801 - 97.050-600 - Santa Maria, RS - joaogaribaldi@brturbo.com.br 
desvalorização da lã, como o colapso da URSS e a crise econômica na Europa Ocidental e na Ásia, que reduziram a demanda de lã no mercado internacional. O público consumidor de tecidos começou também a mudar seus hábitos, deslocando seu consumo para confecções de algodão, sintéticos e misturas de fibras, instalando, desta forma, a crise mundial no setor.

Muitos produtores, nos anos subseqüentes, deixaram a atividade e passaram a investir em outros setores mais rentáveis, o que causou redução drástica no rebanho. Os rebanhos de raças laneiras foram os mais atingidos e acabaram dando espaço para a entrada de raças especializadas em carne.

Apesar das dificuldades enfrentadas nas últimas décadas, a estabilidade monetária conquistada a partir do Plano Real, a abertura do comércio internacional e o aumento do poder aquisitivo da população trouxeram um novo mercado para a ovinocultura. De acordo com Gecomp (2004), a carne ovina tem um sabor diferenciado e é apreciada pelos consumidores, tendo um excelente potencial para se tornar um produto substituto no mercado.

Assim, a produção de carne ovina tem se tornado novamente uma atividade viável para os pecuaristas, porque além de abastecer o consumo das fazendas, há demanda de consumo no mercado interno. Simplício et al. (2003) afirmam que houve um incremento de consumo de carnes ovinas, mas, no entanto, a demanda ainda é reprimida, pois $50 \%$ do consumo do mercado interno são supridos pela carne importada do Mercosul e Nova Zelândia.

O conjunto de mudanças estruturais e conjunturais por que passou a atividade ovina descritos até aqui refletiuse nos preços pagos pelos seus produtos, seja na fase de declínio como de recuperação. Desta forma, por meio deste trabalho busca-se avaliar o comportamento dos preços pagos no Rio Grande do Sul ao produtor pelos principais produtos da ovinocultura, quais sejam, carne de ovelha, carne de cordeiro e lã, no período de 1973 a 2005, enfatizando as características de tendência, sazonalidade e ciclos de preços. Especificamente pretendeu-se comparar o comportamento dos preços antes e após a estabilização da economia brasileira iniciada em 1994. Por esta razão, se estimou os indicadores utilizados no estudo para dois períodos: de 1973 a 1994 e de 1995 a 2005.

\section{MATERIAL E MÉTODOS}

O presente trabalho foi realizado com base nas séries históricas de preços nominais mensais pagos ao produtor pelos produtos ovelha (peso vivo), cordeiro (peso vivo) e lã, coletados pela EMATER/RS e disponibilizados para esta pesquisa por intermédio do Centro Integrado de Ensino, Pesquisa e Extensão Rural - CIEPER, convênio da EMATER/RS com a Universidade Federal de Santa Maria - RS. Os dados abrangem o período de janeiro de 1973 a dezembro de 2005.

O itinerário metodológico partiu da atualização monetária dos preços nominais utilizados na pesquisa. Assim, após fazer as correções monetárias necessárias relativas aos diferentes planos econômicos (Plano Cruzado, Plano Verão, Plano Collor e Plano Real) nos preços nominais históricos, deflacionou-se os preços corrigidos de cada mês de forma a atualizá-los para valores reais equivalentes a dezembro de 2005, utilizando-se a expressão (1). Para o deflacionamento dos preços nominais foi utilizado o Índice Geral de Preços (IGP-DI), calculado pela Fundação Getúlio Vargas, por ser este um índice que reflete tanto preços ao consumidor final como preços nos segmentos das cadeias produtivas e canais de comercialização, classificados como preços no atacado:

$$
\mathrm{PRi}=(\mathrm{PNi} . \mathrm{IPa}) / \mathrm{IPi},
$$

em que: $\mathbf{P R i}=$ preço real no período "i"; $\mathbf{P N i}=$ preço nominal corrigido no período "i”; $\mathbf{I P a}=$ IGP-DI de dezembro de 2005; IPi= IGP-DI no período "i".

A estimativa dos Índices de Estacionalidade e dos Relativos de Ciclo, necessários às análises de sazonalidade e ciclo dos preços pagos ao produtor, seguiu a metodologia de Análise de Séries Temporais preconizada por Kazmier (1982). O Índice de Estacionalidade foi estimado utilizandose o método das médias móveis de 13 meses, que consiste, sucessivamente, nos seguintes passos: a) cálculo da média móvel de treze meses consecutivos de preços; b) cálculo da razão à média móvel, dado pela divisão de cada preço médio mensal pela respectiva média móvel centrada no mês, multiplicando o resultado por 100; c) cálculo da média modificada de cada mês, como sendo a média dos preços do mês após a eliminação dos valores mais alto e mais baixo; e d) estimativa do Índice de Estacionalidade, dado pela multiplicação da média modificada por um fator de correção, de modo que a soma dos índices mensais seja 1.200 , que é o somatório esperado já que a média dos mesmos é, por este método, por definição igual a 100.

Para estimar os Relativos de Ciclo, que permitem avaliar a componente cíclica da série de preços, foi necessário ajustar uma reta de regressão aos dados de preços reais pagos ao produtor, de forma a estimar valores

Ciênc. agrotec., Lavras, v. 31, n. 1, p. 191-199, jan./fev., 2007 
de tendência para cada período de tempo. Tal reta foi ajustada utilizando-se o método dos mínimos quadrados, conforme Johnston (1977), tendo como variável dependente o preço real médio anual desestacionalizado e como variável independente o período de tempo, operacionalizada, esta última, como uma seqüência numérica que representa cada um dos anos analisados (1, 2, 3, 4, 5...). Como observou-se uma reversão de tendência nos preços após 1994, calculou-se duas retas de regressão, uma para os dados de 1973 até 1994 e outra para os dados de 1995 até 2005. Pela regressão, estimou-se os parâmetros "a" e "b" da expressão (2):

$$
\mathrm{PT}=\mathrm{a}+\mathrm{b} . \mathrm{T},
$$

em que: PT = preço de tendência; $\mathbf{a}=$ coeficiente linear da reta de tendência; $\mathbf{b}=$ coeficiente angular da reta de tendência; $\mathbf{T}=$ período de tempo $(1,2,3,4,5 \ldots 33)$.

Como a regressão foi feita com base no preço anual médio desestacionalizado, foi necessário desestacionalizar os preços mensais antes de calcular a média anual, utilizando-se para isso a expressão (3). A desestacionalização permite retirar dos preços mensais as variações estacionais e de curto prazo, deixando na série temporal de preços apenas as variações cíclicas e de tendência, possibilitando, assim, que se faça a regressão com base nos preços médios anuais, o que é mais conveniente e dá mais consistência à regressão:

$$
\mathrm{PDi}=(\mathrm{PRi} / \mathrm{IEi}) .100,
$$

em que: PDi = preço real desestacionalizado no mês "i"; $\mathbf{P R i}=$ preço real no mês “i”; $\mathbf{I E i}=$ Índice de Estacionalidade do mês "i".

Após realizada a regressão, os Relativos de Ciclo foram calculados dividindo-se o valor observado (o preço médio anual desestacionalizado) pelo respectivo valor estimado através da equação de regressão para cada ano (preço de tendência) e multiplicando-se o resultado por 100, conforme a expressão (4):

$$
\text { R.C. }=(\mathrm{PDt} / \mathrm{PTt}) .100 \text {, }
$$

sendo R.C. = Relativo de Ciclo; PDt $=$ preço real desestacionalizado no período "t"; PTt $=$ preço de tendência no período " $\mathrm{t}$ ".

A regressão também foi utilizada para avaliar a existência de tendência ascendente ou declinante na série histórica de preços reais, a qual foi verificada através do teste de hipóteses t-student, com o qual se verificou, a um nível de $95 \%$ de significância, se o coeficiente angular " $b$ " da reta de regressão ajustada aos dados é significativamente diferente de zero. Coeficientes angulares diferentes de zero caracterizam tendência, ascendente se o coeficiente for positivo ou declinante se o coeficiente for negativo.

Por fim, para cada uma das séries de preços analisadas foi também estimado um índice de preço com os preços reais médios anuais, com base 100 em 1973. O índice de preço, na medida que transforma valores absolutos (em unidades monetárias) em valores relativos (sem unidade alguma) fixados em uma mesma base, permite que se possa comparar a evolução das três séries de preços. Além disso, para permitir avaliar os períodos de maior e menor variação de preços, estimou-se a taxa média geométrica de variação anual dos índices de preço ao produtor, por meio da expressão (5), conforme Crusius \& Assis (1992):

$$
\mathrm{Tx}=\left\{\left[(\mathrm{IPn} / \mathrm{IPo})^{1 / \mathrm{n}-1}\right]-1\right\} .100,
$$

em que: $\mathbf{T} \mathbf{x}=$ taxa média geométrica de variação por período; IPn = índice de preço do final do período; IPo = índice de preço do início do período; $\mathbf{n}=$ número de anos do período.

\section{RESULTADOS E DISCUSSÃO}

Conforme se pode observar na Figura 1, os preços reais pagos aos ovinocultores gaúchos por quilograma de peso vivo do cordeiro, da ovelha e da lã apresentaram tendência de queda durante o período de 1973 a 1994, sendo significativo o teste de hipótese do coeficiente angular da equação de regressão. Para este período a taxa média geométrica de variação anual foi de $-3,63 \%,-3,41 \%$ e $-8,06 \%$, respectivamente. De 1995 a 2005 os preços por quilograma de cordeiro e ovelha apresentaram tendência de elevação significativa, sendo a taxa média geométrica de variação anual de $2,89 \%$ e $2,47 \%$, respectivamente. O preço real pago por quilograma da lã no período apresentou anos de crescimento e queda até 2005, alcançando uma taxa média geométrica de variação anual de $-0,98 \%$, não tendo-se observado, porém, tendência estatisticamente significativa.

Fatores já descritos anteriormente, como o aumento da produtividade, o avanço da agricultura, a entrada no mercado de tecidos sintéticos e os altos estoques internacionais de lã explicam não só a tendência de queda do conjunto de preços pesquisados até 1994, como também o declínio mais acentuado do preço da lã em relação aos 
outros produtos. Porém, com a diminuição drástica do rebanho, o aumento na apreciação da carne ovina e a estabilidade econômica do Plano Real, a tendência de queda de preços dos produtos ovinos cessou, apresentando cenário de estabilização e crescimento no período de 1995 a 2005 (Figura 1).

Pela Figura 2, apresentam-se os Relativos de Ciclo (RC) dos preços pagos aos ovinocultores, sendo observada a existência de ciclos irregulares durante o período de 1973 a 1994, com durações entre 4 e 7 anos.
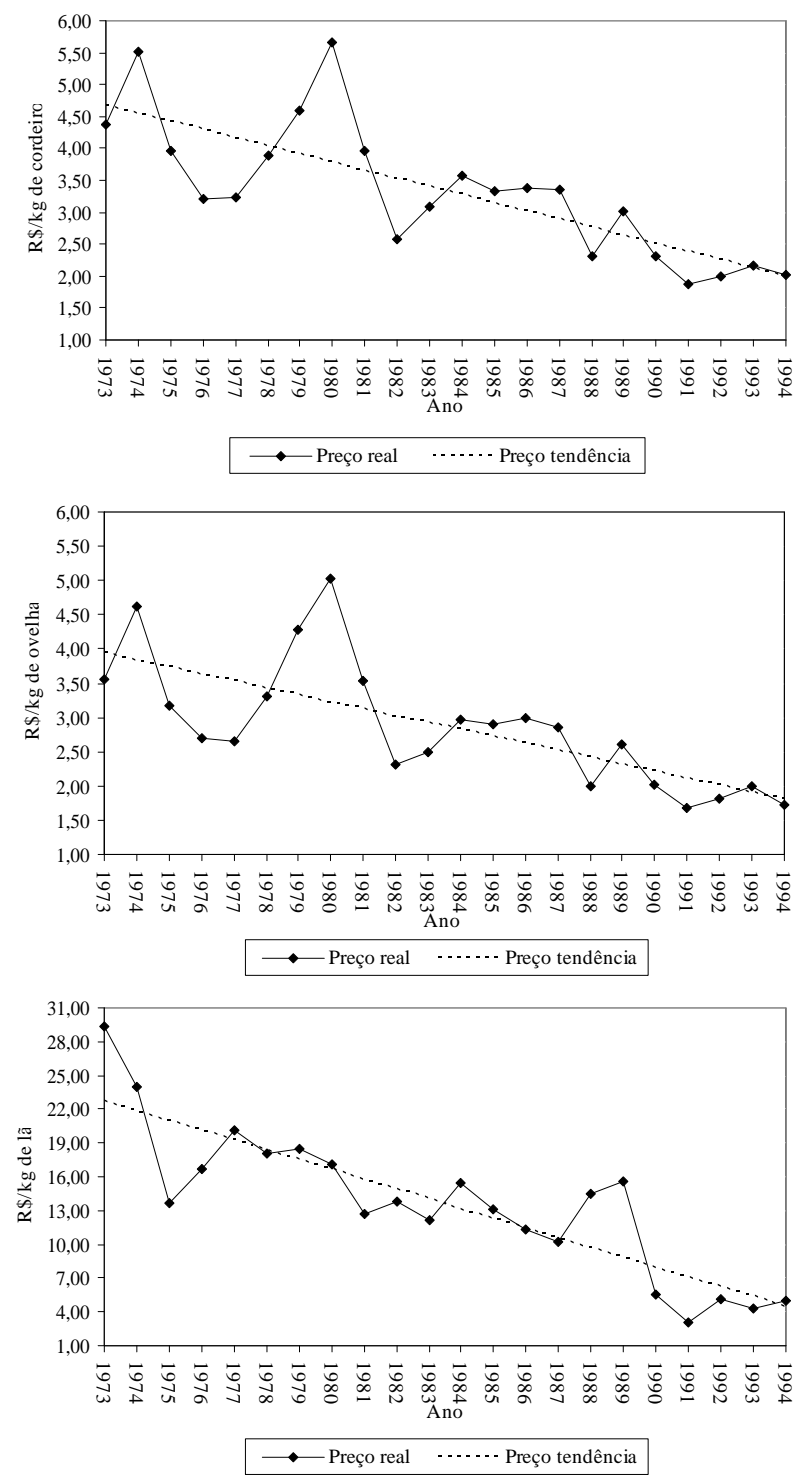

Conforme Nocchi (2001), durante as décadas de 70 e 80 os produtores de lã recebiam crédito subsidiado do governo federal, situação que possibilitava o estoque da lã nas cooperativas e a venda gradativa da produção ao longo do ano, trazendo mais rentabilidade à atividade face à valorização do produto com a inflação.

No ano de 1990, porém, o governo encerrou a política de crédito subsidiado aos ovinocultores, tornando inviável a estocagem do produto, o que reduziu o poder de barganha dos produtores e, somado aos elevados estoques
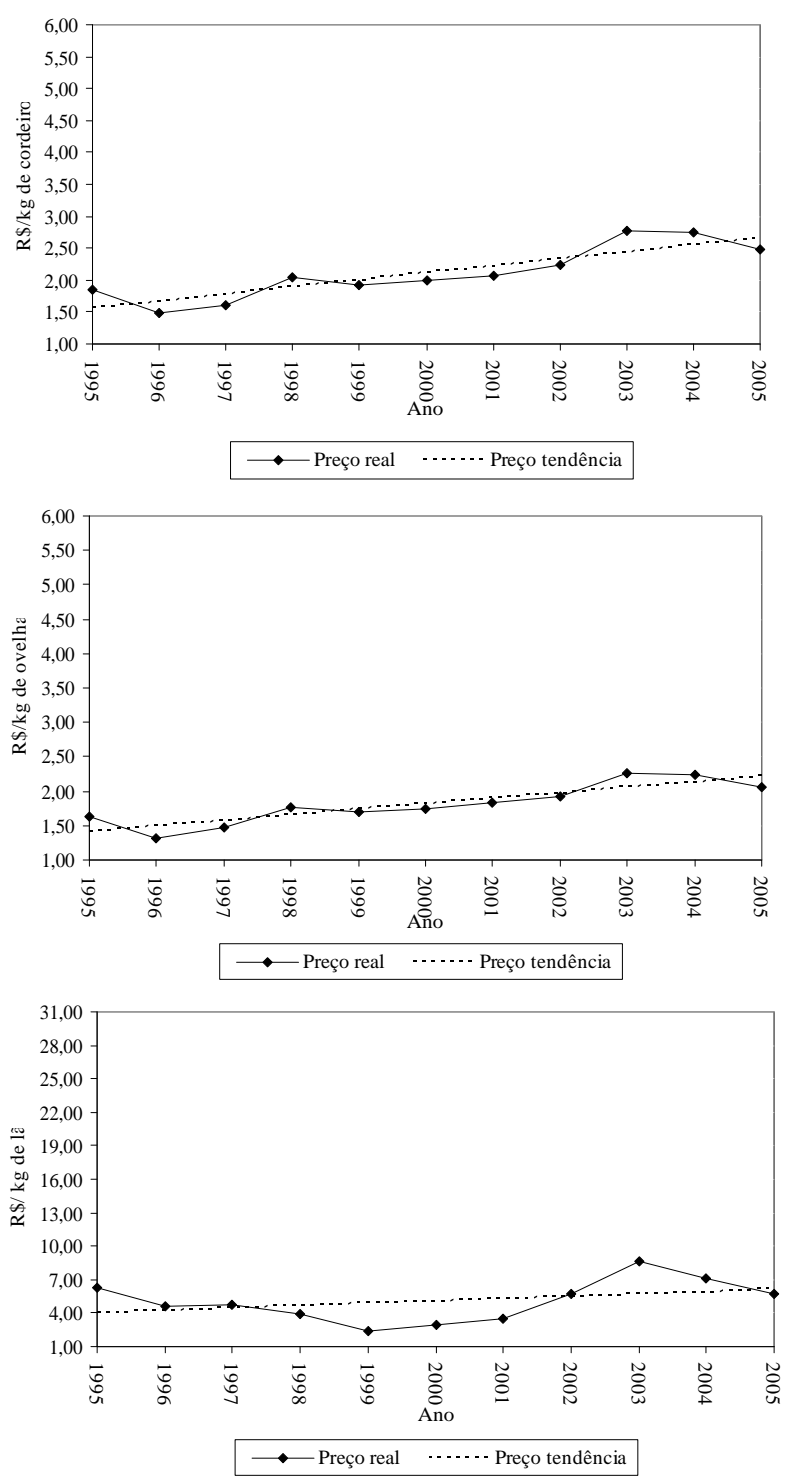

FIGURA 1 - Tendência e preços reais pagos aos ovinocultores gaúchos por quilograma de cordeiro, ovelha e lã, nos períodos 1973-1994 e 1995-2005. DEAER/NEPEA - UFSM, Santa Maria-RS, 2006. 
australianos de lã, contribuiu para deprimir o preço dos produtos. Assim se explica a grande variação nos relativos de ciclo e também nos preços reais verificados nos anos de 1989 e 1990 (Figura 2).

A partir de 1995, os relativos de ciclo dos preços pagos por cordeiro e ovelha apresentaram menor intensidade de variação, o que é característico da maior estabilidade dos preços possibilitada pela estabilização do ambiente econômico.
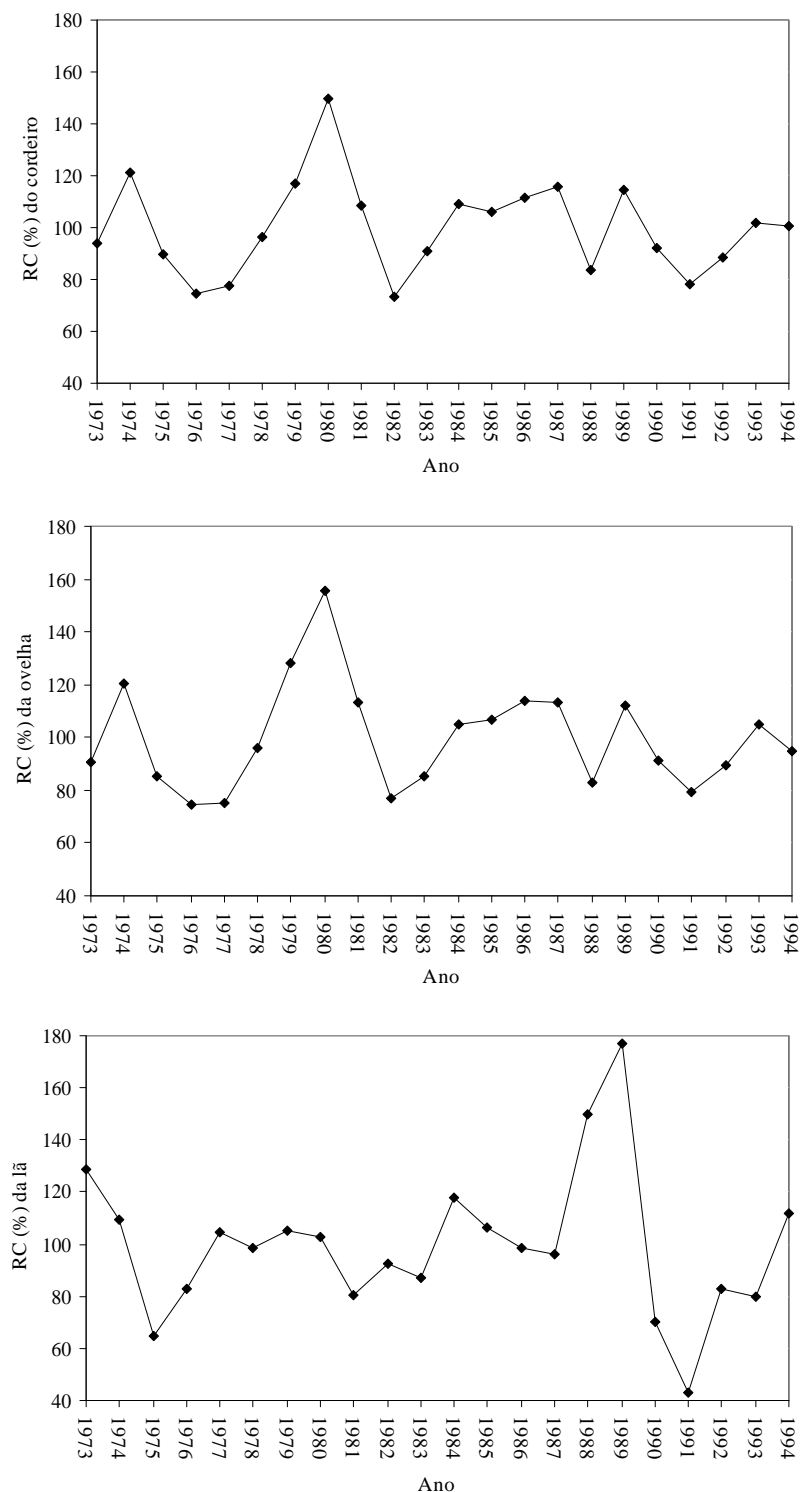

De acordo com a Figura 2, a intensa variação cíclica dos preços da lã no período de 1995 a 2005 é explicada pelo fato do produto ser altamente dependente do mercado internacional, o que os torna sensíveis às intensas variações cambiais ocorridas no período. Este fato também explica a recuperação dos preços reais da lã apenas a partir de em 1999, período que marcou o retorno da valorização do dólar frente ao real.
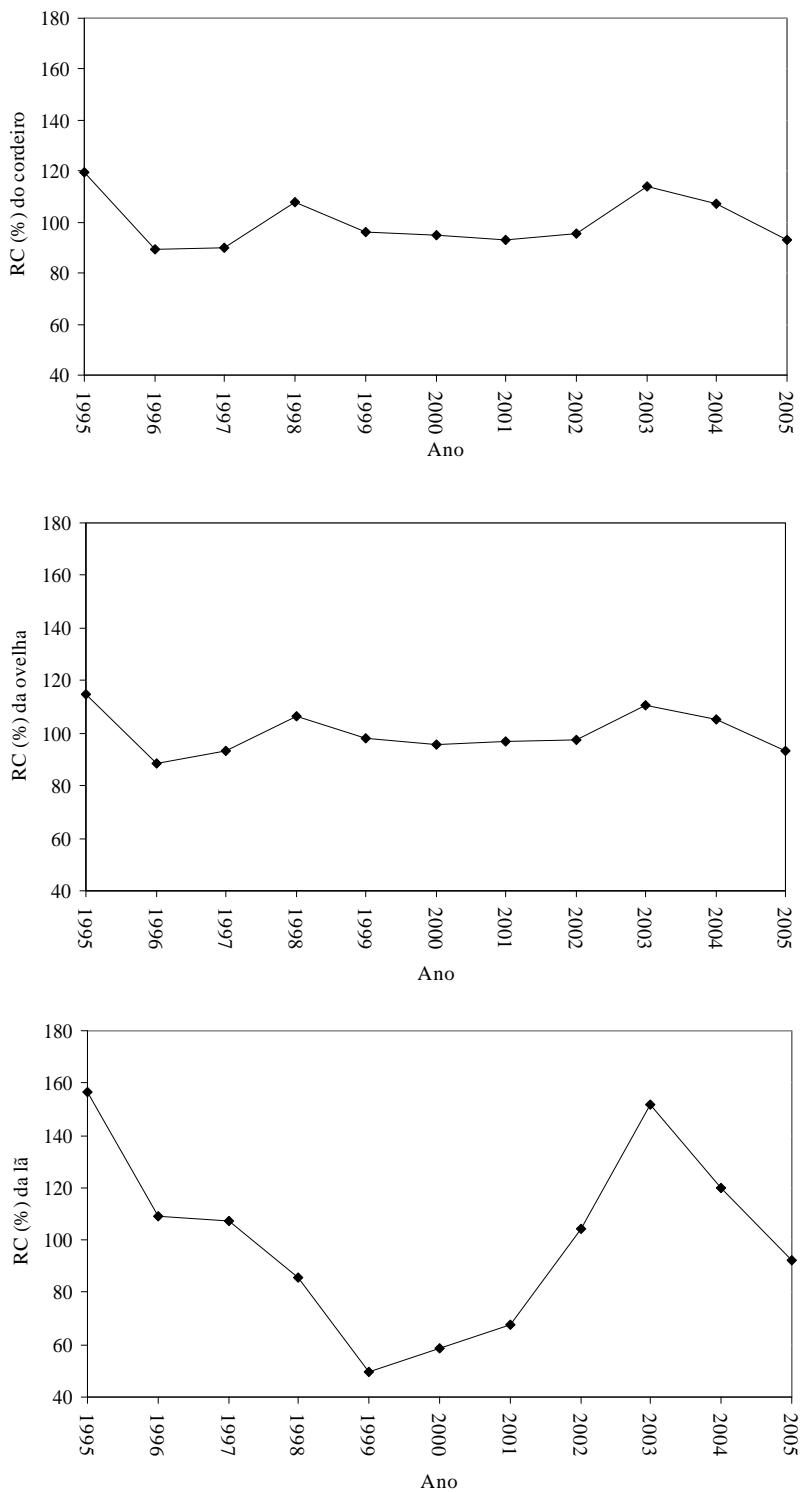

FIGURA 2 - Relativos de Ciclos (RC) dos produtos da ovinocultura de 1973 a 1994 e 1995 a 2005. DEAER/NEPEA UFSM, Santa Maria-RS, 2006. 
A sazonalidade dos preços é expressa na Figura 3 a partir dos Índices de Estacionalidade (IE). Observa-se uma pequena redução da variabilidade estacional dos preços do cordeiro e da ovelha após 1995, em função da adoção de tecnologias que possibilitam maior regularidade da oferta de animais durante o ano, além da estabilidade econômica consolidada no mesmo período.

Os maiores preços pagos por quilograma de cordeiro e ovelha se concentram no mês de dezembro, o que é influenciado pelo aumento da demanda de carne ovina para consumo nas festas de final de ano (Figura 3).

O produto lã apresentou baixa variabilidade estacional nos dois períodos analisados, pelo fato do produto, apesar da adoção de novas tecnologias produtivas, ser caracterizado por apresentar basicamente apenas um período de safra, a tosquia anual de primavera. A partir da década de 90 , com a redução do rebanho e o fim das cooperativas, passou a não ser rentável a estocagem da lã, sendo a venda concentrada no fim do ano, quando o mercado absorve a produção com maiores preços.

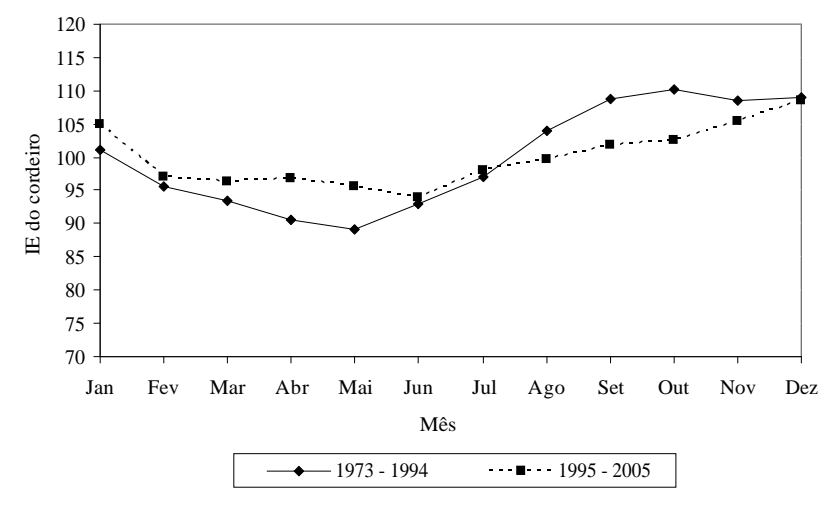

Na Figura 4, mostra-se a comparação da evolução dos preços pagos pelos diferentes produtos da ovinocultura de 1973 a 2004 a partir dos índices de preços, com base 100 em 1973. São observados comportamentos evolutivos similares dos preços do cordeiro e da ovelha em todo o período, com variações de elevação e queda de preço na década de 70 , uma forte queda na década de 80 que se estende até meados da década de 90 , e recuperação com elevação dos mesmos a partir de 1996.

Observa-se também que a lã apresenta uma queda mais acentuada de preço no período em comparação com a carne ovina, sendo que após a crise do setor, entre o final da década de 80 e início da década de 90, os preços apresentaram um comportamento mais estável, sem grandes variações.

Os valores de preços reais pagos aos ovinocultores por quilograma de cordeiro, ovelha e lã, bem como os Relativos de Ciclo (RC), Índices de Preços (IP) e Índices de Estacionalidade para todo o período analisado são apresentados nas Tabelas 1 e 2.

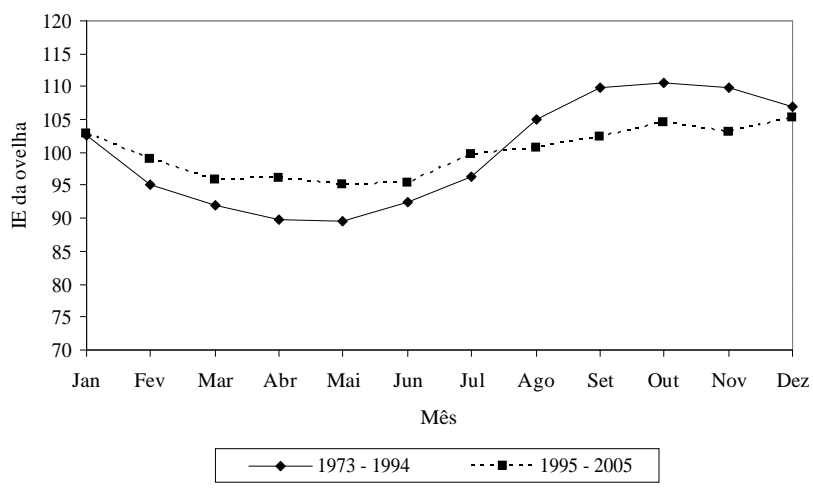

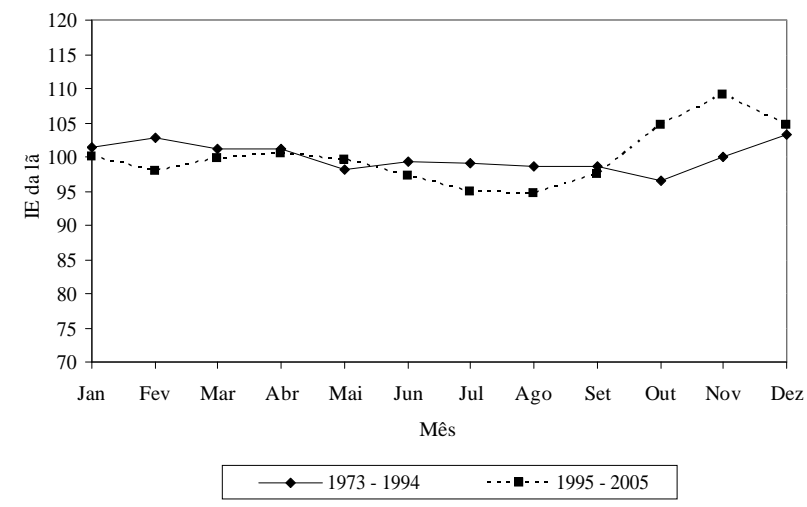

FIGURA 3 - Índices de Estacionalidade (IE) dos produtos da ovinocultura de 1973 a 1994 e 1995 a 2005. DEAER/NEPEA - UFSM, Santa Maria-RS, 2006.

Ciênc. agrotec., Lavras, v. 31, n. 1, p. 191-199, jan./fev., 2007 


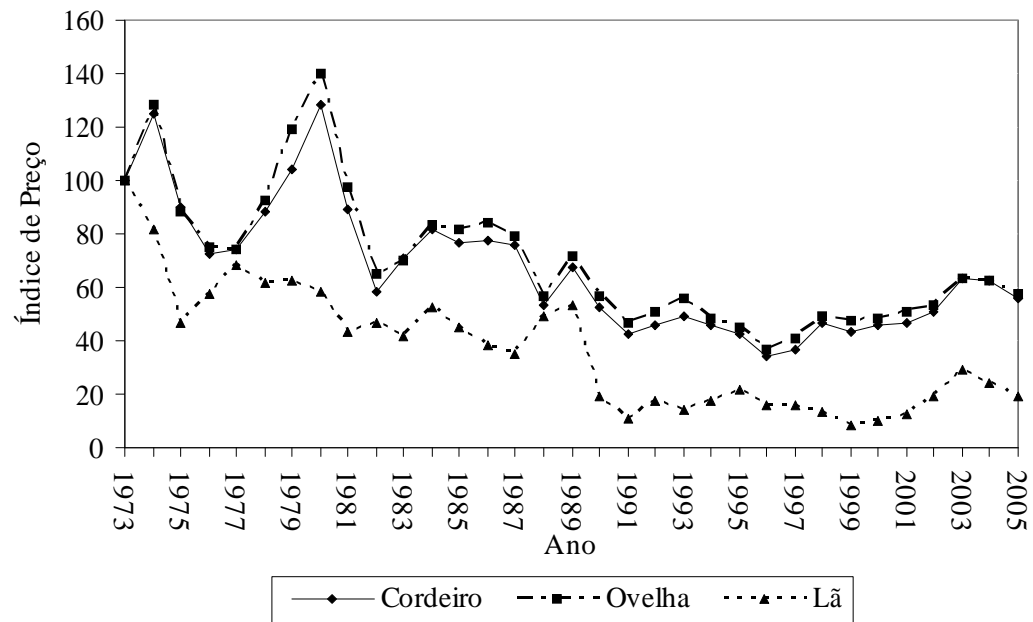

FIGURA 4 - Índices de preço dos produtos da ovinocultura de 1973 a 2005. DEAER/NEPEA - UFSM, Santa Maria-RS, 2006.

TABELA 1 - Preços reais, Relativos de Ciclo (RC) e Índices de Preços (IP) dos produtos da ovinocultura no Rio Grande do Sul de 1973 a 2005. DEAER/NEPEA - UFSM, Santa Maria-RS, 2006.

\begin{tabular}{|c|c|c|c|c|c|c|c|c|c|}
\hline \multirow{2}{*}{$\begin{array}{l}\text { Produto } \\
\text { Ano }\end{array}$} & \multicolumn{3}{|c|}{ Cordeiro } & \multicolumn{3}{|c|}{ Ovelha } & \multicolumn{3}{|c|}{ Lã } \\
\hline & $\mathrm{R} \$ / \mathrm{kg}$ & RC (\%) & IP & $\mathrm{R} \$ / \mathrm{kg}$ & RC (\%) & IP & R\$/kg & RC (\%) & IP \\
\hline 1973 & 4,39 & 93,83 & 100 & 3,58 & 90,64 & 100,00 & 29,27 & 128,91 & 100 \\
\hline 1974 & 5,48 & 121,31 & 124,89 & 4,59 & 120,39 & 128,12 & 23,93 & 109,60 & 81,76 \\
\hline 1975 & 3,95 & 89,84 & 89,94 & 3,16 & 85,26 & 88,29 & 13,62 & 64,95 & 46,56 \\
\hline 1976 & 3,20 & 74,82 & 72,90 & 2,69 & 74,32 & 75,16 & 16,73 & 83,09 & 57,17 \\
\hline 1977 & 3,24 & 77,68 & 73,79 & 2,65 & 75,17 & 74,00 & 20,10 & 104,48 & 68,68 \\
\hline 1978 & 3,88 & 96,08 & 88,30 & 3,30 & 96,26 & 92,27 & 18,09 & 98,38 & 61,80 \\
\hline 1979 & 4,59 & 117,18 & 104,50 & 4,28 & 128,37 & 119,45 & 1841 & 105,26 & 62,92 \\
\hline 1980 & 5,64 & 149,93 & 128,56 & 5,00 & 155,58 & 139,69 & 17,11 & 102,97 & 58,45 \\
\hline 1981 & 3,93 & 108,64 & 89,42 & 3,49 & 113,04 & 97,53 & 12,65 & 80,37 & 43,24 \\
\hline 1982 & 2,58 & 73,22 & 58,71 & 2,32 & 76,80 & 64,80 & 13,73 & 92,32 & 46,92 \\
\hline 1983 & 3,11 & 90,70 & 70,85 & 2,51 & 85,19 & 70,08 & 12,23 & 86,96 & 41,79 \\
\hline 1984 & 3,58 & 109,01 & 81,56 & 2,97 & 105,18 & 83,05 & 15,48 & 117,71 & 52,88 \\
\hline 1985 & 3,35 & 106,16 & 76,27 & 2,92 & 106,82 & 81,45 & 13,08 & 106,48 & 44,69 \\
\hline 1986 & 3,39 & 111,68 & 77,23 & 3,00 & 113,88 & 83,82 & 11,26 & 98,76 & 38,47 \\
\hline 1987 & 3,34 & 115,93 & 76,09 & 2,83 & 113,07 & 79,12 & 10,17 & 96,34 & 34,74 \\
\hline 1988 & 2,34 & 83,87 & 53,39 & 2,01 & 82,96 & 56,34 & 14,50 & 149,59 & 49,54 \\
\hline 1989 & 2,98 & 114,41 & 67,88 & 2,57 & 112,38 & 71,72 & 15,56 & 176,81 & 53,18 \\
\hline 1990 & 2,31 & 92,42 & 52,62 & 2,02 & 91,44 & 56,36 & 5,57 & 70,19 & 19,02 \\
\hline 1991 & 1,87 & 78,37 & 42,72 & 1,68 & 79,12 & 46,86 & 3,07 & 43,19 & 10,48 \\
\hline 1992 & 2,01 & 88,70 & 45,77 & 1,81 & 89,64 & 50,68 & 5,14 & 82,88 & 17,57 \\
\hline 1993 & 2,17 & 101,64 & 49,44 & 2,00 & 104,91 & 56,07 & 4,26 & 79,87 & 14,57 \\
\hline 1994 & 2,02 & 100,55 & 45,97 & 1,73 & 95,00 & 48,19 & 5,00 & 111,97 & 17,10 \\
\hline 1995 & 1,85 & 119,52 & 42,19 & 1,61 & 114,58 & 45,04 & 6,24 & 156,44 & 21,31 \\
\hline 1996 & 1,49 & 89,50 & 33,94 & 1,32 & 88,47 & 36,82 & 4,60 & 109,38 & 15,72 \\
\hline 1997 & 1,59 & 89,72 & 36,34 & 1,47 & 93,31 & 40,98 & 4,74 & 107,23 & 16,19 \\
\hline
\end{tabular}

TABELA 1 - Continua ... 
TABELA 1 - Continuação ...

\begin{tabular}{l|ccc|ccc|ccc}
\hline 1998 & 2,03 & 108,00 & 46,34 & 1,76 & 106,35 & 49,01 & 3,96 & 85,66 & 13,52 \\
1999 & 1,91 & 96,13 & 43,59 & 1,70 & 98,25 & 47,36 & 2,42 & 49,88 & 8,27 \\
2000 & 2,00 & 95,05 & 45,54 & 1,73 & 95,64 & 48,28 & 2,97 & 58,75 & 10,16 \\
2001 & 2,05 & 92,74 & 46,78 & 1,83 & 97,02 & 51,13 & 3,56 & 67,71 & 12,18 \\
2002 & 2,23 & 95,65 & 50,87 & 1,92 & 97,65 & 53,68 & 5,72 & 104,22 & 19,56 \\
2003 & 2,78 & 114,05 & 63,37 & 2,26 & 110,54 & 63,22 & 8,63 & 151,89 & 29,49 \\
2004 & 2,74 & 107,46 & 62,52 & 2,23 & 104,92 & 62,20 & 7,07 & 119,96 & 24,17 \\
2005 & 2,46 & 93,01 & 56,09 & 2,06 & 93,55 & 57,52 & 5,65 & 92,57 & 19,30 \\
\hline
\end{tabular}

TABELA 2 - Índices de Estacionalidade (IE) dos preços pagos aos ovinocultores do Rio Grande do Sul de 1973 a 2005. DEAER/NEPEA - UFSM, Santa Maria-RS, 2006.

\begin{tabular}{|c|c|c|c|c|c|c|}
\hline \multirow[t]{2}{*}{ Período } & \multicolumn{2}{|c|}{ Cordeiro } & \multicolumn{2}{|c|}{ Ovelha } & \multicolumn{2}{|c|}{ Lã } \\
\hline & 1973 - 1994 & 1995 - 2005 & 1973 - 1994 & $1995-2005$ & 1973 - 1994 & 1995 - 2005 \\
\hline Janeiro & 101,10 & 104,82 & 102,57 & 102,75 & 101,37 & 99,99 \\
\hline Fevereiro & 95,57 & 96,94 & 95,04 & 98,94 & 102,78 & 97,79 \\
\hline Março & 93,48 & 96,21 & 91,88 & 95,89 & 101,13 & 99,74 \\
\hline Abril & 90,47 & 96,79 & 89,74 & 96,13 & 101,05 & 100,53 \\
\hline Maio & 89,04 & 95,61 & 89,66 & 95,18 & 98,12 & 99,47 \\
\hline Junho & 93,07 & 93,83 & 92,56 & 95,36 & 99,38 & 97,09 \\
\hline Julho & 97,02 & 98,01 & 96,31 & 99,70 & 99,02 & 94,91 \\
\hline Agosto & 103,88 & 99,59 & 104,91 & 100,58 & 98,65 & 94,57 \\
\hline Setembro & 108,77 & 101,79 & 109,95 & 102,46 & 98,62 & 97,50 \\
\hline Outubro & 110,25 & 102,55 & 110,50 & 104,55 & 96,48 & 104,68 \\
\hline Novembro & 108,40 & 105,37 & 109,88 & 103,19 & 100,03 & 109,06 \\
\hline Dezembro & 108,94 & 108,47 & 107,01 & 105,26 & 103,36 & 104,64 \\
\hline
\end{tabular}

\section{CONCLUSÕES}

Mudanças estruturais e econômicas afetaram o comportamento dos preços pagos aos ovinocultores ao longo das últimas décadas, o que implicou em reduções reais de preços e influenciou na desistência de muitos produtores da atividade. Observou-se que a lã foi o produto mais afetado pela queda nos preços, o que implicou em queda na rentabilidade de toda a atividade em função da importância que o produto assumia em todo o sistema produtivo.

Entretanto, a estabilização econômica do Plano Real, a partir de 1994, e suas conseqüências no mercado interno, fizeram com que a carne ovina se tornasse o produto principal da ovinocultura, apresentando considerável elevação de preços nos últimos dez anos. Observou-se também que este período foi marcado por redução na intensidade das variações interanuais e sazonais de preços, ou seja, de ano para ano e dentro do ano.
Pode-se dizer, então, que após 1995 a ovinocultura passa por uma recuperação de preços em termos reais e por uma estabilização nos mercado, o que aumenta a rentabilidade e reduz os riscos da atividade. Assim, com melhores remunerações e menores riscos, a produção ovina voltou a ser uma boa alternativa aos pecuaristas nos últimos anos.

\section{REFERÊNCIAS BIBLIOGRÁFICAS}

BOFILL, F. J. A reestruturação da ovinocultura gaúcha. Guaíba: Ed. Agropecuária, 1996. 137 p.

CRUSIUS, C.; ASSIS, A. L. de. Cálculos com índices: índices, fatores e taxas. 2. ed. Porto Alegre: GECE/FCE/ UFRGS, 1992. (Série manuais GECE, 1).

GECOMP. Análise econômica da ovinocultura no Distrito Federal: grupo de estudos sobre a competitividade e sustentabilidade do agronegócio, Universidade de Brasília. Brasília, DF: UnB, 2004. 83 p. Relatório final de pesquisa. 
JOHNSTON, J. Métodos econométricos. São Paulo: Atlas, 1977. 313 p.

KAZMIER, L. J. Estatística aplicada à economia e administração. São Paulo: McGraw-Hill, 1982. 376 p.

NOCCHI, E. D. Os efeitos da crise da lã no mercado internacional e os impactos sócio-econômicos no município de Santana do Livramento, RS, Brasil. 2001. 71 f. Dissertação (Mestrado em Integração e Cooperação Internacional) - Universidad Nacional de Rosario, Rosario, 2001.

SIMPLÍCIO, A. A. et al. A Caprino-ovinocultura de corte como alternativa para a geração de emprego e renda. Sobral: Embrapa Caprinos, 2003. 44 p. (Documentos online 48). Disponível em: '<http://www.cnpc.embrapa.bri DOC48.pdf $>$. Acesso em: 3 mar. 2006. 